\title{
Highly Dynamic Chalcogen Chains in Silver(I) (Poly)Chalcogenide Halides: a New Concept for Thermoelectrics?
}

\author{
T. NILGES, ${ }^{1,2}$ M. BAWOHL, ${ }^{1}$ S. LANGE ${ }^{1}$ J. MESSEL,${ }^{1}$ and O. OSTERS ${ }^{1}$ \\ 1.--Institute of Inorganic and Analytical Chemistry, University of Muenster, Muenster, Germany. \\ 2._e-mail: nilges@uni-muenster.de
}

Coinage-metal(I) polychalcogenide halides represent a new class of materials featuring high ion dynamics of different substructures capable of an effective phonon scattering process in the solid state. The interplay of mobile coinagemetal ions such as $\mathrm{Ag}^{+}$or $\mathrm{Cu}^{+}$on the one hand and the temperature-driven redox reaction of a linear, partially covalent-bonded Te chain on the other hand is responsible for tremendous variations in the electronic structure of such materials. A huge drop of the Seebeck coefficient within a very small temperature range and an extremely low thermal conductivity are the key properties of $\mathrm{Ag}_{10} \mathrm{Te}_{4} \mathrm{Br}_{3}$, the first representative of this substance class. Two different sets of compounds with the general formula $(\mathrm{CM})_{10} \mathrm{Q}_{4} \mathrm{X}_{3}$ and $(\mathrm{CM}){ }_{23} \mathrm{Q}_{12} \mathrm{X}(\mathrm{CM}=$ coinage metal $\mathrm{Cu}$ or $\mathrm{Ag}, \mathrm{Q}=$ chalcogen, $\mathrm{X}=$ halogen $)$ have been found, and recent experiments point toward the existence of formerly unknown copper(I) (poly)chalcogenide halides and two more silver(I) (poly)chalcogenide halides in this field. A comparable linear Te chain is present in a number of different compounds such as some alkaline-earth polychalcogenides $\mathrm{M}_{5} \mathrm{Te}_{3}$, the mineral stuetzite $\mathrm{Ag}_{4.5} \mathrm{Te}_{3}$, and the closely related compounds $\mathrm{Ag}_{11} \mathrm{AsTe}_{7}$ and $\mathrm{Ag}_{12} \mathrm{Te}_{6} \mathrm{~S}$. In most cases the thermoelectric potential of these materials has not been verified. A topological approach for the description of the structural features has been developed to understand the electronic properties of these complex materials in detail.

Key words: Redox switches, chalcogen chains, ion dynamics, polychalcogenide halides, structure topology, effective phonon scattering

\section{INTRODUCTION}

A process that is capable of generating effective phonon scattering in solids is suitable to improve materials for thermoelectric devices in energyconversion applications. Recently, Sales ${ }^{1}$ wrote a manuscript reviewing the progress in this field. He stated: "It will probably be necessary to reduce kappa and to improve the power factor in a bulk material in order to achieve a material at a

Dedicated to Prof. Dr. Dr. h.c. M. Jansen on the occasion of his 65th birthday.

(Received June 4, 2009; accepted October 23, 2009; published online November 20, 2009) reasonable cost that is efficient enough for many commercial applications." He pointed out that new ideas and concepts need to be found and developed to reach this goal. Even more critical statements are discussed in the literature regarding the future of thermoelectrics in general, ${ }^{2}$ e.g., that materials featuring $Z T$ values $>2$ using quantum $\operatorname{dots}^{3}$ and superlattices $^{4-6}$ are not ready to be produced on the commercial scale. It is also highly questionable how sintering of nanostructured materials can be avoided at high temperature and gradients, or how production costs can be reduced to make nanostructured materials suitable for large-scale applications. Herein we give a brief statement on the structural and thermoelectric features of a new 
class of highly effective phonon-scattering materials characterized by high dynamics of different building blocks in the solid state. A partially covalent-bonded polyanion substructure seems to play a major role in this scattering process. The important covalent and ionic character of this group is denoted by the parentheses in the term "(poly)anion" used herein. Probably, the introduction of highly dynamic and well-defined (poly)chalcogenide chains in the case of the coinage-metal (poly)chalcogenide halides is a promising feature to decrease the heat transport, determined by the crystalline lattice vibrations, to as close to zero as possible. All results and features reported herein are based on nonoptimized bulk material without nanostructuring, which probably implies a reasonable chance of commercial application of these thermoelectric materials for efficient energyconversion processes.

\section{EXPERIMENTAL PROCEDURES}

All coinage-metal (poly)chalcogenide halides were prepared by common solid-state high-temperature synthesis of stoichiometric mixtures of the starting materials (CM)X, Q, and CM. The starting materials were heated to $1200 \mathrm{~K}$ in evacuated silica ampoules and quenched thereafter prior to a homogenization and annealing process at temperatures between $650 \mathrm{~K}$ and $750 \mathrm{~K}$. Each annealing step lasted several days at temperatures below the respective peritectic decomposition temperatures. The phase-purity of the resulting compounds was checked by x-ray powder-phase analysis, and the homogenization and annealing process was repeated until a phase-pure sample was achieved. More detailed information concerning the preparation conditions can be found in the literature (see citations in the "Results and Discussion" section).

The thermal diffusivity of $\mathrm{Ag}_{20} \mathrm{Te}_{10} \mathrm{BrI}$ was measured in the temperature range from $223 \mathrm{~K}$ to $424 \mathrm{~K}$ using a Netzsch Micro flash LFA 457. A pellet of $10 \mathrm{~mm}$ diameter and $1.32 \mathrm{~mm}$ thickness was examined under He gas flow of $100 \mathrm{~mL} / \mathrm{min}$. The pellet was prepared from a powdered sample of $\mathrm{Ag}_{20} \mathrm{Te}_{10} \mathrm{BrI}$ by cold pressing (pressure $\sim 6000$ $\mathrm{kg} \mathrm{cm}{ }^{-2}$ ), achieving $98 \%$ of the x-ray density. Five independent measurements were performed and averaged at each temperature. A MCT detector (HgCdTe) was used for detection, and the software packet Proteus (Netzsch, Germany) was applied to analyze the resulting raw data.

Thermal analysis was performed using a Netzsch DSC 204 machine. Finely ground $\mathrm{Ag}_{20} \mathrm{Te}_{10} \mathrm{BrI}$ was placed into an aluminum crucible and measured in the temperature range of $113 \mathrm{~K}$ to $800 \mathrm{~K}$. All experiments were conducted under nitrogen atmosphere. We found no evidence for a structural phase transition prior to the peritectic decomposition at 702(1) K, which is characterized by an endothermic thermal effect.
Semiquantitative analysis of $\mathrm{Ag}_{20} \mathrm{Te}_{10} \mathrm{BrI}$ was performed using a Leica 420i scanning electron microscope (Zeiss) fitted with an energy-dispersive x-ray (EDX) unit (Oxford). A voltage of $20 \mathrm{kV}$ was applied to the samples, and silver, $\mathrm{HgTe}$ (Te), and $\mathrm{NaBr}$ were used for calibration proposes. The results averaged from different single crystals in at.\% were Ag:Te:Br:I = 64(2):35(2):1(2):1(2). It has to be stated at this point that the measured ratio is relatively close to the theoretical values of Ag:Te:Br:I = 62.5:31.25:3.125:3.125. Nevertheless, the at.\% fraction of each halide is very close to the detection limit of the EDX unit, and the x-ray intensities of $\mathrm{Te}$ and I coincide for most of the lines. Therefore this result should be interpreted with care.

Crystal structure analyses of a selected single crystal of $\mathrm{Ag}_{20} \mathrm{Te}_{10} \mathrm{BrI}$ were performed at $293 \mathrm{~K}$ and $150 \mathrm{~K}$ on a IPDS II diffractometer (Stoe). It was equipped with a Mo x-ray source $(\lambda=0.71073 \AA)$ and the temperature was controlled by a Cryostream Plus system (Oxford). Intensity data were corrected for Lorentz and polarization effects prior to a numerical absorption correction based on an optimized description of the crystal shape. ${ }^{7}$

Table I. Crystallographic data of $\operatorname{Ag}_{20} \mathrm{Te}_{10} \mathrm{BrI}$ at $293 \mathrm{~K}$ and $150 \mathrm{~K}$

\begin{tabular}{|c|c|c|}
\hline & $293 \mathrm{~K}$ & $150 \mathrm{~K}$ \\
\hline Empirical formula & \multicolumn{2}{|c|}{$\mathrm{Ag}_{20} \mathrm{Te}_{10} \mathrm{BrI}$} \\
\hline Refined formula & $\mathrm{Ag}_{20.1} \mathrm{Te}_{10} \mathrm{BrI}$ & $\mathrm{Ag}_{20.5} \mathrm{Te}_{10} \mathrm{BrI}$ \\
\hline Molar mass (g mole ${ }^{-1}$ ) & 3654.7 & 3695.2 \\
\hline \multicolumn{3}{|l|}{ Unit cell dimensions } \\
\hline$a(\AA)$ & $27.682(2)$ & $27.584(2)$ \\
\hline$b(\AA)$ & $16.2328(8)$ & $16.1549(7)$ \\
\hline$c(\AA)$ & $7.5932(8)$ & $7.5535(5)$ \\
\hline$\beta\left(^{\circ}\right)$ & $105.870(7)$ & $105.885(5)$ \\
\hline Unit cell volume $\left(\AA^{3}\right)$ & $3282.0(5)$ & $3237.5(3)$ \\
\hline$Z$ & 4 & \\
\hline Density $\left(\mathrm{g} \mathrm{cm}^{-3}\right)$ & 7.394 & 7.579 \\
\hline Crystal size $(\mathrm{mm})$ & $\begin{array}{c}0.06 \times 0.045 \\
\times 0.04\end{array}$ & $\begin{array}{c}0.06 \times 0.045 \\
\times 0.04\end{array}$ \\
\hline Space group & $C 2 / c$ & \\
\hline$\theta$ range & $1.47-27.95$ & $1.47-28.21$ \\
\hline$h k l$ range & $\begin{array}{l}-34 \text { to } 36 \\
-21 \text { to } 19 \\
-10 \text { to } 6\end{array}$ & $\begin{array}{l}-34 \text { to } 36 \\
-21 \text { to } 17 \\
-9 \text { to } 9\end{array}$ \\
\hline Total reflections, $R_{\text {int }}$ & 0.0325 & 0.0348 \\
\hline No. of parameters & 532 & 550 \\
\hline $\begin{array}{l}\text { Independent } \\
\quad \text { reflections, } R(\sigma)\end{array}$ & $3665,0.0633$ & $3140,0.0352$ \\
\hline \multicolumn{3}{|l|}{$\begin{array}{l}\text { Final } R \text { indices } \\
{[I>3 \sigma I]}\end{array}$} \\
\hline$R 1$ & 0.0538 & 0.0616 \\
\hline $\mathrm{w} R 2$ & 0.0704 & 0.0868 \\
\hline \multicolumn{3}{|l|}{$R$ indices (all data) } \\
\hline$R 1$ & 0.1203 & 0.0888 \\
\hline $\mathrm{w} R 2$ & 0.0794 & 0.0898 \\
\hline Extinction coefficient & \multicolumn{2}{|c|}{ None } \\
\hline $\begin{array}{l}\text { Largest diff. peak } \\
\text { and hole }\left(\mathrm{e} \AA^{-3}\right)\end{array}$ & $2.18 /-1.49$ & $2.80 /-1.75$ \\
\hline
\end{tabular}


Table II. Atomic coordinates, site occupancy factors (SOF), and isotropic displacement parameters $\left(\AA^{2}\right)$ of $\mathrm{Ag}_{20} \mathrm{Te}_{10} \mathrm{BrI}$ at $293 \mathrm{~K}$ and $150 \mathrm{~K}$

\begin{tabular}{|c|c|c|c|c|c|}
\hline Atom & SOF & $x$ & $y$ & $z$ & $U_{\text {iso }}$ \\
\hline \multicolumn{6}{|l|}{$293 K$} \\
\hline $\mathrm{Te} 1$ & 1 & $0.03823(3)$ & $0.12074(7)$ & $0.0382(2)$ & $0.0464(3)$ \\
\hline $\mathrm{Te} 2$ & 1 & $0.15174(3)$ & $0.06320(6)$ & $0.6520(2)$ & $0.0431(3)$ \\
\hline Te3 & 1 & $0.20796(3)$ & $0.23350(7)$ & $0.2079(2)$ & $0.0509(4)$ \\
\hline $\mathrm{Te} 4$ & 1 & $0.10755(4)$ & $0.30683(6)$ & $0.6073(2)$ & $0.0504(4)$ \\
\hline Te5 & 0.5 & $0.29432(7)$ & $-0.0003(1)$ & $0.4796(4)$ & $0.0479(8)$ \\
\hline Te6 & 0.5 & $0.29416(7)$ & $0.0004(1)$ & $0.6088(4)$ & $0.0475(8)$ \\
\hline I1 & 0.5 & $0.05772(4)$ & $0.39829(8)$ & $0.0580(2)$ & $0.0573(5)$ \\
\hline $\mathrm{Br} 1$ & 0.5 & 0.0577 & 0.3983 & 0.058 & $0.0573(5)$ \\
\hline Ag1 & $0.429(9)$ & $0.1070(4)$ & $0.2484(7)$ & $0.262(2)$ & $0.116(4)$ \\
\hline Ag2 & $0.37(1)$ & $0.2045(3)$ & $0.0768(7)$ & $0.355(2)$ & $0.129(4)$ \\
\hline Ag3 & $0.345(8)$ & $0.2009(3)$ & $0.3389(8)$ & $-0.141(2)$ & $0.155(4)$ \\
\hline $\mathrm{Ag} 4$ & $0.380(8)$ & $0.0599(2)$ & $0.1392(7)$ & $-0.355(2)$ & $0.126(5)$ \\
\hline Ag5 & $0.397(8)$ & $0.0692(3)$ & $0.1458(8)$ & $0.432(2)$ & $0.118(3)$ \\
\hline Ag6 & $0.321(9)$ & $0.1964(2)$ & $0.2146(6)$ & $0.601(2)$ & $0.105(5)$ \\
\hline $\mathrm{Ag} 7$ & $0.365(9)$ & $0.1955(2)$ & $0.2187(6)$ & $0.784(2)$ & $0.112(5)$ \\
\hline Ag8 & $0.398(8)$ & $0.0427(3)$ & $0.4316(6)$ & $0.411(2)$ & $0.103(3)$ \\
\hline Ag9 & $0.335(9)$ & $0.2004(5)$ & $0.0818(7)$ & $1.030(2)$ & $0.105(4)$ \\
\hline Ag10 & $0.388(8)$ & $0.1065(3)$ & $0.2537(4)$ & $0.966(1)$ & $0.088(2)$ \\
\hline Ag11 & $0.35(1)$ & $0.0583(5)$ & $0.0254(8)$ & $-0.248(2)$ & $0.112(5)$ \\
\hline Ag12 & $0.354(8)$ & $0.2003(3)$ & $0.3410(7)$ & $0.536(2)$ & $0.154(5)$ \\
\hline Ag13 & $0.45(1)$ & $0.1059(5)$ & $0.1825(5)$ & $-0.129(2)$ & $0.127(4)$ \\
\hline Ag14 & $0.71(1)$ & $-0.0125(4)$ & $0.2779(6)$ & $-0.009(4)$ & $0.52(2)$ \\
\hline Ag15 & $0.39(1)$ & $0.0585(4)$ & $0.025(1)$ & $0.369(2)$ & $0.135(4)$ \\
\hline Ag16 & $0.333(9)$ & $0.1085(6)$ & $0.185(1)$ & $0.343(2)$ & $0.100(4)$ \\
\hline Ag17 & $0.19(1)$ & $0.253(1)$ & $0.059(2)$ & $0.750(4)$ & $0.18(1)$ \\
\hline Ag18 & $0.437(8)$ & $0.0498(4)$ & $0.4344(7)$ & $0.683(1)$ & $0.139(4)$ \\
\hline Ag19 & $0.31(1)$ & $0.1094(4)$ & $0.471(1)$ & $0.840(2)$ & $0.154(7)$ \\
\hline Ag20 & $0.337(9)$ & $0.1500(9)$ & $0.0998(7)$ & $0.273(1)$ & $0.101(6)$ \\
\hline Ag21 & $0.354(8)$ & $0.2319(3)$ & $0.1365(6)$ & $0.526(2)$ & $0.102(3)$ \\
\hline Ag22 & $0.346(8)$ & $0.1526(2)$ & $0.3603(5)$ & $0.312(2)$ & $0.125(4)$ \\
\hline Ag23 & $0.315(9)$ & $0.1552(5)$ & $0.0933(6)$ & $0.028(1)$ & $0.136(5)$ \\
\hline Ag24 & $0.332(8)$ & $0.1536(4)$ & $0.3622(7)$ & $0.001(2)$ & $0.132(5)$ \\
\hline Ag25 & $0.34(1)$ & $0.1101(4)$ & $0.462(1)$ & $0.395(2)$ & $0.145(5)$ \\
\hline Ag26 & $0.372(9)$ & $0.2346(3)$ & $0.1374(4)$ & $0.896(2)$ & $0.152(6)$ \\
\hline Ag27 & $0.21(1)$ & $0.1230(8)$ & $0.4776(9)$ & $0.642(3)$ & $0.23(1)$ \\
\hline Ag28 & $0.38(1)$ & 0 & $0.506(2)$ & 0.25 & $0.23(1)$ \\
\hline \multicolumn{6}{|l|}{$150 \mathrm{~K}$} \\
\hline Te1 & 1 & $0.03761(3)$ & $0.11998(6)$ & $0.0374(1)$ & $0.0295(3)$ \\
\hline Te2 & 1 & $0.15345(4)$ & $0.06336(6)$ & $0.6533(1)$ & $0.0331(3)$ \\
\hline Te3 & 1 & $0.20699(4)$ & $0.23506(8)$ & $0.2064(2)$ & $0.0502(4)$ \\
\hline $\mathrm{Te} 4$ & 1 & $0.10865(4)$ & $0.30582(6)$ & $0.6084(1)$ & $0.0385(3)$ \\
\hline Te5 & 0.5 & $0.29525(8)$ & $0.00007(14)$ & $0.4809(3)$ & $0.0367(7)$ \\
\hline Te6 & 0.5 & $0.29527(8)$ & $-0.0004(2)$ & $0.6109(2)$ & $0.0374(7)$ \\
\hline I1 & 0.5 & $0.05682(7)$ & 0.3986(1) & $0.0569(2)$ & $0.0585(5)$ \\
\hline $\mathrm{Br} 1$ & 0.5 & 0.0568 & 0.3986 & 0.0569 & $0.0585(5)$ \\
\hline $\mathrm{Ag} 1$ & $0.467(7)$ & $0.1061(4)$ & $0.2453(5)$ & $0.257(1)$ & $0.094(3)$ \\
\hline Ag2 & $0.35(1)$ & $0.2083(6)$ & $0.0820(9)$ & $0.397(1)$ & $0.084(4)$ \\
\hline Ag3 & $0.288(8)$ & $0.2002(3)$ & $0.3353(8)$ & $-0.120(2)$ & $0.082(3)$ \\
\hline $\mathrm{Ag} 4$ & $0.450(7)$ & $0.0591(3)$ & $0.1379(6)$ & $-0.3562(8)$ & $0.093(3)$ \\
\hline Ag5 & $0.432(8)$ & $0.0684(2)$ & $0.1518(6)$ & $0.4296(8)$ & $0.091(2)$ \\
\hline Ag6 & $0.361(8)$ & $0.1993(4)$ & $0.2134(7)$ & $0.596(2)$ & $0.082(3)$ \\
\hline $\mathrm{Ag} 7$ & $0.336(8)$ & $0.1972(2)$ & $0.2171(7)$ & $0.813(2)$ & $0.056(2)$ \\
\hline Ag8 & $0.45(1)$ & $0.0416(3)$ & $0.4232(8)$ & $0.408(1)$ & $0.102(3)$ \\
\hline Ag9 & $0.368(9)$ & $0.2017(4)$ & $0.0819(6)$ & $0.034(2)$ & $0.095(3)$ \\
\hline Ag10 & $0.463(8)$ & $0.1024(2)$ & $0.2487(9)$ & $0.960(2)$ & $0.074(3)$ \\
\hline Ag11 & $0.47(1)$ & $0.0609(4)$ & $0.0116(7)$ & $-0.237(2)$ & $0.110(4)$ \\
\hline Ag12 & $0.32(1)$ & $0.1997(3)$ & $0.3419(6)$ & $0.543(1)$ & $0.153(4)$ \\
\hline Ag13 & $0.40(1)$ & $0.1071(5)$ & $0.1750(5)$ & $-0.138(1)$ & $0.068(3)$ \\
\hline Ag14 & $0.51(1)$ & $-0.0097(2)$ & $0.2707(5)$ & $-0.011(3)$ & $0.257(8)$ \\
\hline
\end{tabular}


Table II. Continued

\begin{tabular}{|c|c|c|c|c|c|}
\hline Atom & SOF & $x$ & $\boldsymbol{y}$ & $z$ & $U_{\text {iso }}$ \\
\hline Ag15 & $0.45(1)$ & $0.0619(4)$ & $0.0153(7)$ & $0.367(2)$ & $0.100(3)$ \\
\hline Ag16 & $0.329(7)$ & $0.1124(3)$ & $0.1773(5)$ & $0.343(1)$ & $0.045(2)$ \\
\hline Ag17 & $0.203(8)$ & $0.2600(5)$ & $0.067(2)$ & $0.760(2)$ & $0.114(7)$ \\
\hline Ag18 & $0.474(9)$ & $0.0472(4)$ & $0.4359(6)$ & $0.653(1)$ & $0.130(3)$ \\
\hline Ag19 & $0.34(1)$ & $0.1094(4)$ & $0.4634(5)$ & $0.832(2)$ & $0.116(5)$ \\
\hline Ag20 & $0.339(8)$ & $0.1533(7)$ & $0.0977(3)$ & $0.275(1)$ & $0.078(5)$ \\
\hline Ag21 & $0.37(1)$ & $0.2296(5)$ & $0.1306(9)$ & $0.525(1)$ & $0.085(4)$ \\
\hline Ag22 & $0.279(8)$ & $0.1499(3)$ & $0.3657(9)$ & $0.296(2)$ & $0.093(4)$ \\
\hline Ag23 & $0.301(8)$ & $0.1563(4)$ & $0.0890(7)$ & $1.0219(6)$ & $0.102(4)$ \\
\hline Ag24 & $0.330(8)$ & $0.1487(3)$ & $0.3653(9)$ & $-0.006(2)$ & $0.096(4)$ \\
\hline Ag25 & $0.35(1)$ & $0.1107(4)$ & $0.4609(7)$ & $0.385(2)$ & $0.133(4)$ \\
\hline Ag26 & $0.426(8)$ & $0.2349(3)$ & $0.1454(6)$ & $0.908(1)$ & $0.122(3)$ \\
\hline Ag27 & $0.17(1)$ & $0.124(1)$ & $0.484(1)$ & $0.634(4)$ & $0.18(1)$ \\
\hline Ag28 & $0.45(2)$ & 0 & $0.505(2)$ & 0.25 & $0.36(2)$ \\
\hline
\end{tabular}

The structure was solved with direct methods and refined $^{8}$ using a nonharmonic approach ${ }^{9}$ for the description of the silver displacement parameters. The halide position was identified by subsequent refinement of the occupancy factor of all anion positions. Only for one position did the occupancy factor drop significantly if Te was refined on the sites. In good accordance with related compounds ${ }^{10-23}$ where the halide is well separated from the chalcogenide substructure we refined the position with the low scattering power as a halide position. The best results were achieved if the ideal ratio of $\mathrm{Br}$ to $\mathrm{I}=1: 1$ was assumed for this position. In order to verify the quality of our assumptions and the reliability of the structure determination we refined the occupancy factors of all silver positions without any restriction. The refined composition is in very good agreement with the ideal composition, as presented in Table I. A general refinement strategy for such compounds has been discussed earlier. ${ }^{16} \mathrm{Ag}_{20} \mathrm{Te}_{10} \mathrm{BrI}$ crystallizes monoclinically in the space group $C 2 / c$ with lattice parameters of $a=27.682(2) \AA, b=16.2328(8) \AA, c=7.5932(8) \AA$, $\beta=105.870(7)^{\circ}$, and $V=3282.0(5) \AA^{3}$ at $293 \mathrm{~K}$, and of $a=27.584(2) \AA, \quad b=16.1549(7) \AA, \quad c=$ 7.5535(5) $\AA, \beta=105.885(5)^{\circ}$, and $V=3237.5(3) \AA^{3}$ at $150 \mathrm{~K}$. A detailed summary of the crystallographic data is given in Tables I and II. Further information is available from Fachinformationszentrum Karlsruhe, 76344 Eggenstein-Leopoldshafen (Germany), quoting depository numbers CSD-380373 (293 K) and CSD-380372 (150 K).

\section{RESULTS AND DISCUSSION}

In order to understand the electronic properties of the coinage-metal (poly)chalcogenide halides a deep and full understanding of the structural features is necessary. Recently the exploration of new phases and members of the coinage-metal chalcogenide halides such as $\mathrm{Ag}_{5} \mathrm{Q}_{2} \mathrm{X},{ }^{10-15} \mathrm{Ag}_{19} \mathrm{Q}_{6} \mathrm{X}_{7},{ }^{16,17}$ and the new class of coinage-metal (poly)chalcogenide halides such as $\mathrm{Ag}_{10} \mathrm{Q}_{4} \mathrm{X}_{3}$ with $\mathrm{Q}=\mathrm{S}$, Se or Te and $\mathrm{X}=\mathrm{Cl}, \mathrm{Br}$ or $\mathrm{I}^{18-21}$ or $\mathrm{Ag}_{23} \mathrm{Te}_{12} \mathrm{X}$ with $\mathrm{X}=\mathrm{Cl}, \mathrm{Br}^{22}$ demanded a new approach to structure description due to their complexity and the high grade of dynamic disorder within the cation and anion substructures. Defining and following a simple topological principle the cation, anion, and polyanion substructures of the coinage-metal (poly)chalcogenide halides should be described separately. Isolated anions should be connected at distances around the sum of the van der Waals radii to form chains, honeycomb $6^{3}$ (chalcogenide) or Kagomé-like 3.6.3.6 nets (halogenide), while the cations act as the coordinating species to separate the resulting units at usual bond lengths. The polyanion substructure can now be illustrated separately, forming chains built up by isolated $\mathrm{Q}^{2-}$ ions and/or $\left[\mathrm{Q}_{2}\right]^{2-}$ dumbbells. Different linear units such as isolated $\left[\mathrm{Q}_{2}\right]^{2-}$ dumbbell chains or slightly more complex -Q$\left[\mathrm{Q}_{2}\right]-\mathrm{Q}$ - strands result. Figure 1 illustrates the structural features of the (poly)anion substructures of $\mathrm{Ag}_{10} \mathrm{Te}_{4} \mathrm{Br}_{3},{ }^{19} \mathrm{Ag}_{4.53} \mathrm{Te}_{3}$ (stuetzite), ${ }^{24}$ and $\mathrm{Ag}_{12} \mathrm{Te}_{6} \mathrm{~S}^{25}$ applying this principle. The close structural relation of comparable units according to this topological approach becomes obvious. In the present case (poly)anionic Q chains, coordinated by the coinage metal in different fashions and its accommodation within the noncovalently bonded anion substructure, can be identified at once. The cations (not shown in Fig. 1) are highly disordered and coordinate the different anion substructures in a comparable way in all cases. Such a topological approach is useful in three different ways:

1. As a useful tool for the structure solution of these compounds

Twinning caused by polymorphism, huge translation periods with several hundred atoms per unit cell, in combination with low scattering power at higher diffraction angles are common features of these classes of compounds. These aspects prevent 


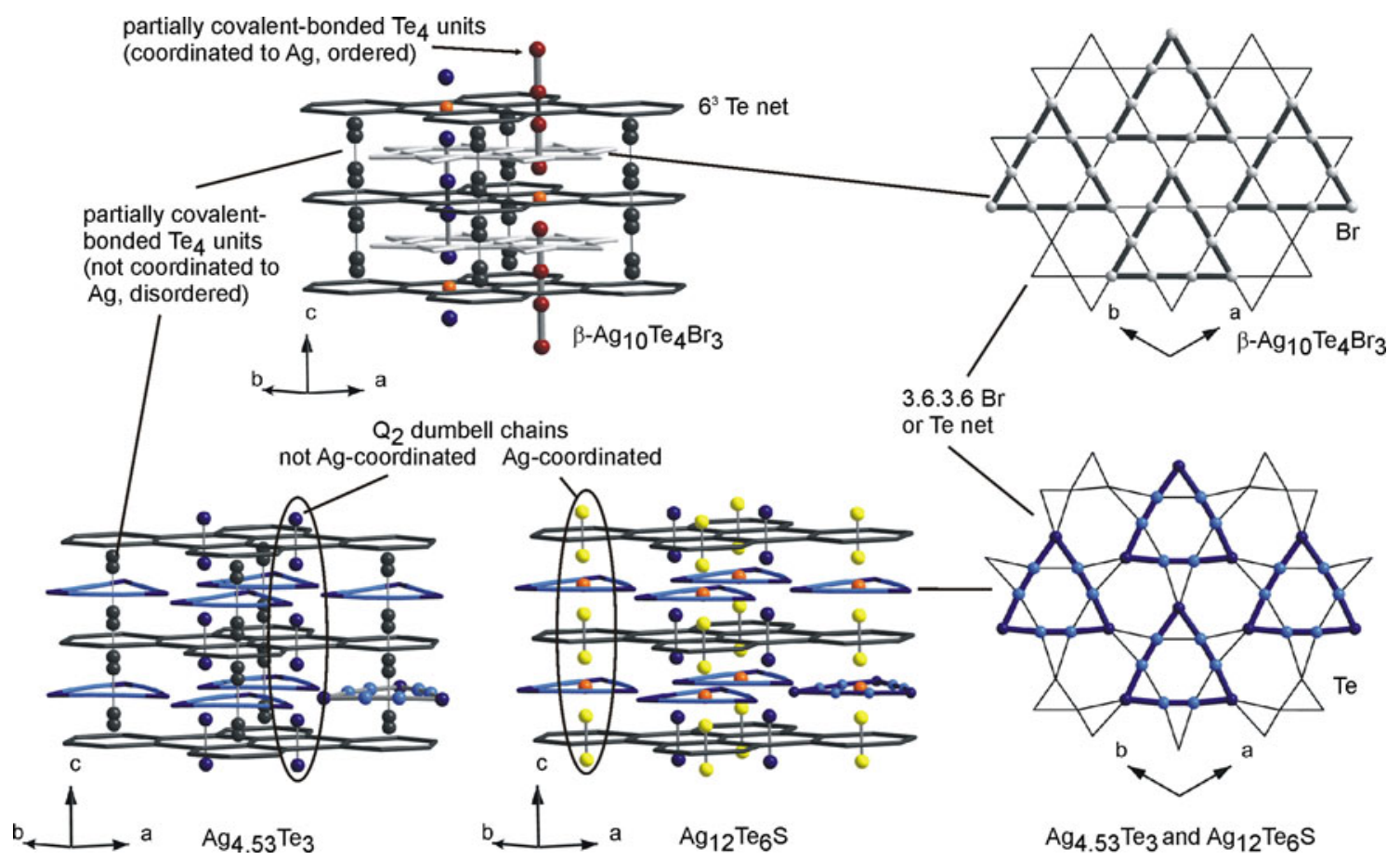

Fig. 1. Topological relations between $\beta-\mathrm{Ag}_{10} \mathrm{Te}_{4} \mathrm{Br}_{3},{ }^{19}$ stuetzite $\left(\mathrm{Ag}_{4.53} \mathrm{Te}_{3}\right),{ }^{24}$ and $\mathrm{Ag}_{12} \mathrm{Te}_{6} \mathrm{~S} .{ }^{25}$ Polyanion substructure: Predominantly covalentbonded linear Te chains form $\mathrm{Te}_{4}$ units. These units are drawn as black (disordered), blue, and red (ordered) spheres. A topological relation of $\left[\left(\mathrm{Te}_{2}\right) \mathrm{Te}\right]_{3}$ units (triangularly connected $\mathrm{Te}_{4}$ units) in $\mathrm{Ag}_{4.53} \mathrm{Te}_{3}$ and $\mathrm{Ag}_{12} \mathrm{Te}_{6} \mathrm{~S}$, compared with the Kagomé-type 3.6.3.6 bromide nets in $\beta-\mathrm{Ag}_{10} \mathrm{Te}_{4} \mathrm{Br}_{3}$, can be observed. [Te $]_{2}^{2-}$ units (denoted as light-blue dumbbells) and $\left[\mathrm{S}_{2}\right]^{2-}$ units (yellow dumbbells) form a linear $\mathrm{Q}_{2}$ chain which is sometimes coordinated by Ag. Anion substructure: Isolated $\mathrm{Te}^{2-}$ and $\mathrm{Br}^{-}$ions are connected at distances around the sum of the van der Waals radii by solid dark-grey or light-grey lines to form $6^{3}$ and 3.6.3.6 nets, respectively. Further atoms in the figure are silver (orange spheres) and sulfur (yellow spheres).

the use of direct, Patterson, and charge-flipping methods in some cases. If so, electron density maps cannot be interpreted properly after solving the structures by using commonly used structuresolution routines based on single-crystal data, and even more so based on powder data. Due to the reduced scattering power of silver atoms, which partially occupy the sites within the unit cell, differentiation between silver and all sites covered by atoms with scattering power lower than that of silver is not possible. Even the charge-flipping approach, which is suitable for solving structures from powder ${ }^{26,27}$ or single-crystal data, implemented in modern computer programs such as JANA 2006 (superflip), ${ }^{28,29}$ does not lead to an interpretable starting model.

2. As a formalism to understand some of the physical properties of these compounds

The different mobile coinage-metals tend to be distributed in an anisotropic way in the coinagemetal chalcogenides and (poly)chalcogenide halides under discussion. Using the mentioned formalism of a quasilayered arrangement of building blocks, the anisotropy of the cations and the anisotropic ion mobility can be explained properly. In the case of $\mathrm{Ag}_{5} \mathrm{Q}_{2} \mathrm{X}$ and $\mathrm{Ag}_{23} \mathrm{Q}_{12} \mathrm{X}$ a noncorrugated or corrugated arrangement of interpenetrating honeycomb $6^{3}-\mathrm{Q}$ nets is interpenetrated by $\mathrm{X}$ chains. For
$\mathrm{Ag}_{5} \mathrm{Q}_{2} \mathrm{X}$ a one-dimensional evolution of silver conductivity in the direction of the halide chains was found. $^{30,31}$ The pronounced two-dimensional mobility and transport of the coinage metal in the case of $\mathrm{Ag}_{10} \mathrm{Q}_{4} \mathrm{X}_{3}$ is now consistent with the layered arrangement of honeycomb Q nets and Kagomé-like $\mathrm{X}$ nets (Fig. 1).

3. To identify and interpret the polyanionic part of anion substructures

Taking structure topological aspects into account a simple Peierls-like arrangement of covalently bonded $\left[\mathrm{Q}_{2}\right]^{2-}$ and isolated $\mathrm{Q}^{2-}$ ions can be identified as the building block of the polyanion substructure in the coinage-metal (poly)chalcogenide halides. ${ }^{19}$ In all cases the charge balance is realized by a rearrangement of silver ions coordinating the $\mathrm{Q}$ chains, and semiconducting behavior can be expected. The mobility of the polyanionic chains causes disorder and frustration in the structure, which leads to closely neighboring and not fully occupied positions in the model derived from averaging diffraction experiments. Diffuse scattering phenomena are common for such behavior, substantiating the accuracy of the averaged structure models. Applying a Peierls model for the mobile Q chain with partially covalent interactions, as in the case of $\mathrm{Ag}_{10} \mathrm{Te}_{4} \mathrm{Br}_{3}$, a band-structure modulation could be predicted and substantiated in that case. 


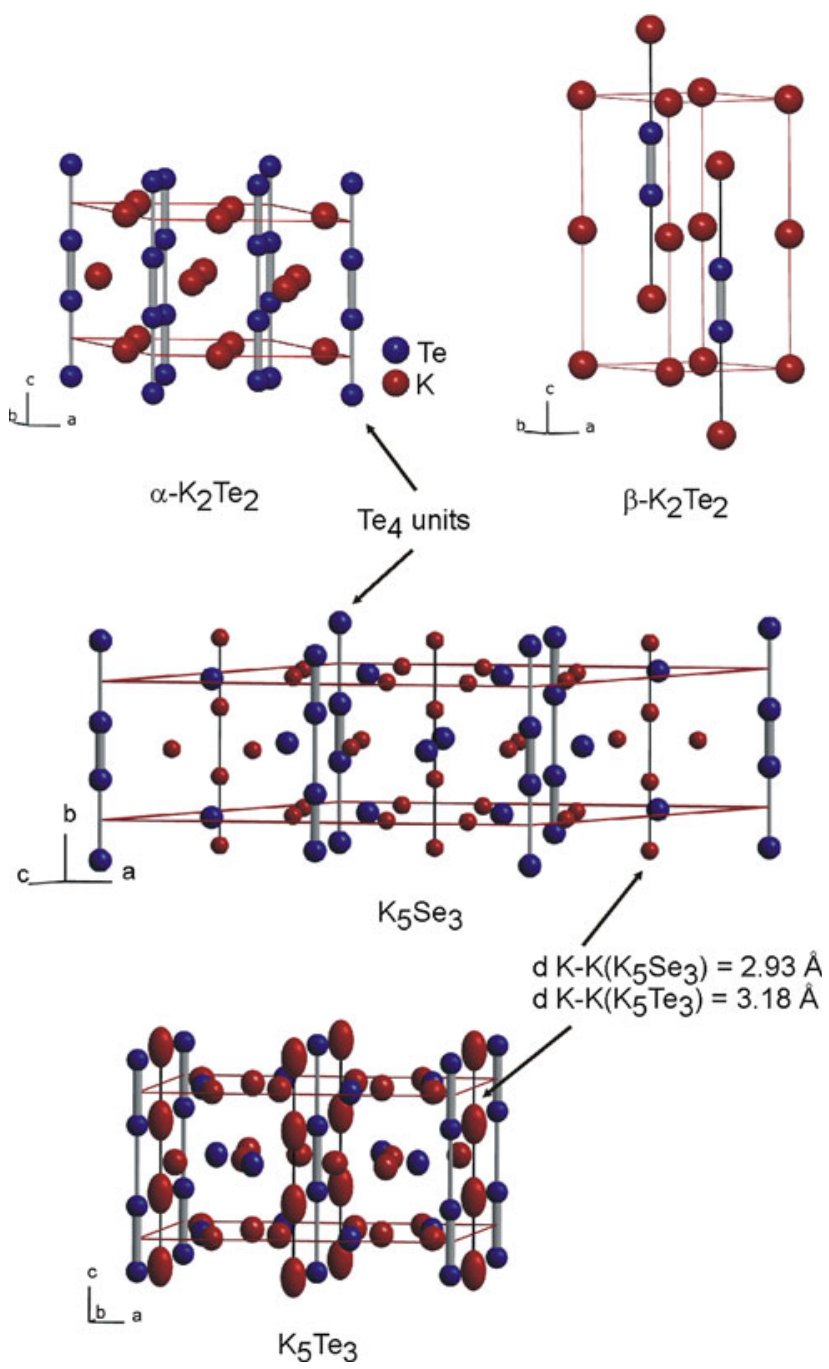

Fig. 2. Topological aspects of potassium (poly)tellurides. $\mathrm{Te}_{4}$ units or K-coordinated $\left[\mathrm{Te}_{2}\right]^{2-}$ dumbbells are present in $\alpha-\mathrm{K}_{2} \mathrm{Te}_{2}$ and $\beta-\mathrm{K}_{2} \mathrm{Te}_{2}{ }^{34}$ These units can also be found in $\mathrm{K}_{5} \mathrm{Q}_{3}$ with $\mathrm{Q}=\mathrm{Se}$, $\mathrm{Te}^{34,35}$ Very short $\mathrm{K}$ distances and high displacements are unusual findings in these structure models, which can be easily avoided by a replacement of $\mathrm{K}$ by $\mathrm{Te}$. The respective smeared-out electron density should then be interpreted as polyanionic disordered Te strands as in the case of the coinage-metal (poly)telluride halides.

Even more compounds such as $\mathrm{Ag}_{4.53} \mathrm{Te}_{3}$ (stuetzite ${ }^{24}$ and the closely related $\mathrm{Ag}_{11} \mathrm{AsTe}_{7}{ }^{32}$ contain such a (poly)anion substructure which could not be interpreted and identified properly before. For stuetzite no sharp order-disorder phase transition of silver ions can be observed, but a structural transition was postulated based on detailed electrochemical experiments at about $513 \mathrm{~K}$ to $553 \mathrm{~K}^{33}$ The occurrence of switching in the Te chains is at least a possible mechanism for this transition, which can be derived from its comparable structural features. In the case of $\mathrm{Ag}_{12} \mathrm{Te}_{6} \mathrm{~S}$ the disordered Te chain is substituted by a silver-coordinated $\mathrm{S}^{2-}$ chain, avoiding the structural disorder and frustration (see the discussion later on in the text). ${ }^{25}$
Some unusual structural and physical properties have been reported for $\mathrm{M}_{5} \mathrm{Q}_{3}$ compounds with $\mathrm{M}=\mathrm{K}$ or $\mathrm{Cs}$ and $\mathrm{Q}=\mathrm{Se}$ or Te. ${ }^{34-36}$ A quite surprising and unbelievable structural feature of $\mathrm{M}_{5} \mathrm{Q}_{3}$ compounds is the very short distance of some $\mathrm{K}$ sites $(d=2.9 \AA$ to $3.2 \AA$, $30 \%$ less than in the element) $)^{34,35}$ or Cs sites in the structure models (Fig. 2). This observation becomes understandable if the $\mathrm{K}$ sites (full occupancy in $\mathrm{K}_{5} \mathrm{Te}_{3}$ ) or Cs sites (occupancy factor of 0.75 in $\mathrm{Cs}_{5} \mathrm{Te}_{3}$ ) of interest are interpreted as linear polyanionic Q chains. Such an estimation would lead to a composition close to KTe, or better $\mathrm{K}_{2} \mathrm{Te}_{2}$, and would set some calculated properties ${ }^{36}$ such as the equilibrium volume per atom of $38.71 \AA^{3}$ for " $\mathrm{K}_{5} \mathrm{Te}_{3}$ " in the right place between $\alpha$ - and $\beta-\mathrm{K}_{2} \mathrm{Te}_{2}{ }^{37}$ (linear chains of $\mathrm{Te}^{2-}$ dumbbells; $43.66 \AA^{3}$ and $42.70 \AA^{3}$ ) and $\mathrm{K}_{2} \mathrm{Te}_{3}{ }^{38}$ (chains of $\left[\mathrm{Te}_{3}\right]^{2-}$ units, $38.32 \AA^{3}$ ). ${ }^{36}$ Also some features in the partial density of states (DOS) of the K3 site of " $\mathrm{K}_{5} \mathrm{Te}_{3}$ " such as the sharp high peak just at the Fermi level ${ }^{36}$ become understandable if partially covalent-bonded $\mathrm{Te}$ is present on this site instead of K. Such a replacement would result in minimal Te-Te distances not shorter than $3.42 \AA$ in $\mathrm{K}_{5} \mathrm{Te}_{3}$ between the chains and neighboring $\mathrm{Te}$ positions. This assumption needs to be verified and addressed by additional experiments, which are not within the scope of this work.

To the best of our knowledge, none of the aforementioned compounds, except the evaluation of the thermomagnetic properties and the magneticfield dependence of the Seebeck coefficient of stuetzite, ${ }^{39,40}$ were examined according their thermoelectric properties.

Based on this simple but fundamental structural approach an interpretation of the unexpected electronic and thermoelectric properties of the coinagemetal (poly)chalcogenide halides can be achieved.

$\mathrm{Ag}_{10} \mathrm{Te}_{4} \mathrm{Br}_{3}$, the first representative ${ }^{18}$ of this class of materials, is a tetramorphic system ${ }^{16}$ with four polymorphs in the small temperature range of $290 \mathrm{~K}$ to $390 \mathrm{~K}$. Chains of Te-[Te 2 ]-Te units coordinated linearly by $\mathrm{Ag}$ run perpendicular to alternating $6^{3}$ Te and 3.6.3.6 Br nets. The occurrence of diffuse scattering phenomena for the two hightemperature polymorphs is in good accordance with a model of an emerging Peierls distortion of a linear [-Te-[Te 2$]-\mathrm{Te}-\mathrm{Ag}-]_{n}$ chain (see Fig. 1 for $\mathrm{Ag}_{10} \mathrm{Te}_{4} \mathrm{Br}_{3}$ and Fig. 3 for the general mechanism) after the temperature-driven removal of the silver ions within the chain. The Peierls distortion causes frustration of neighboring strands according to the exact position of the covalently bonded Te subunits along the strand direction and relative to the surrounding substructure. Such frustration of neighboring chains is comparable to an Ising spin system in magnetic materials from a structural point of view. ${ }^{41}$ This feature causes a split arrangement of half-occupied and closely neighboring Te positions in the structure model of $\mathrm{Ag}_{10} \mathrm{Te}_{4} \mathrm{Br}_{3}$. Exactly the same properties, the diffuse scattering and a 


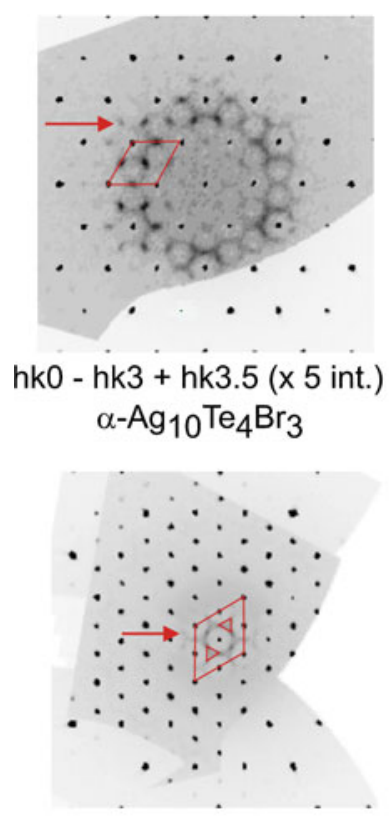

Peierls distorted Te-chain after removal
of the linearly coordinating silver ions

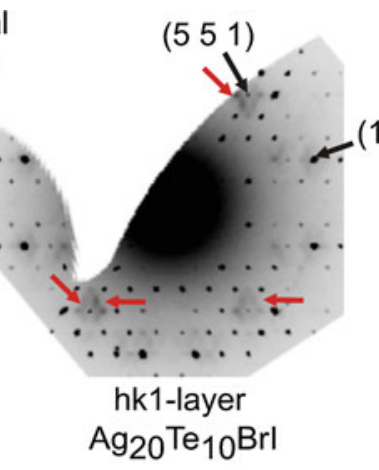

$$
\begin{gathered}
\text { hk0 - hk4 + hk5 (x } 2 \text { int.) } \\
\beta-\mathrm{Ag}_{10} \mathrm{Te}_{4} \mathrm{Br}_{3}
\end{gathered}
$$

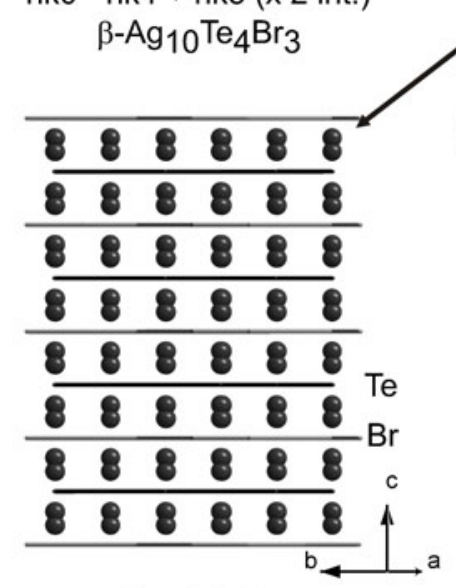
$\alpha-\mathrm{Ag}_{10} \mathrm{Te}_{4} \mathrm{Br}_{3}$
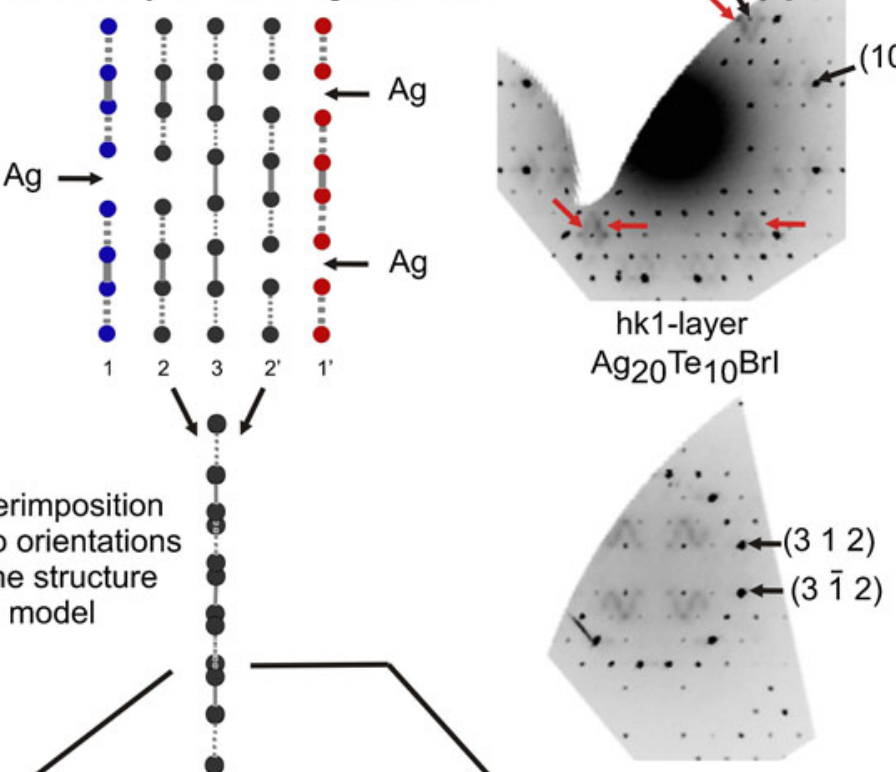

hk3-layer

$\mathrm{Ag}_{20} \mathrm{Te}_{10} \mathrm{Brl}$

of two orientations

in the structure model

$$
210 \mathrm{~T}_{3}
$$

a

$\beta-\mathrm{Ag}_{10} \mathrm{Te}_{4} \mathrm{Br}_{3}$
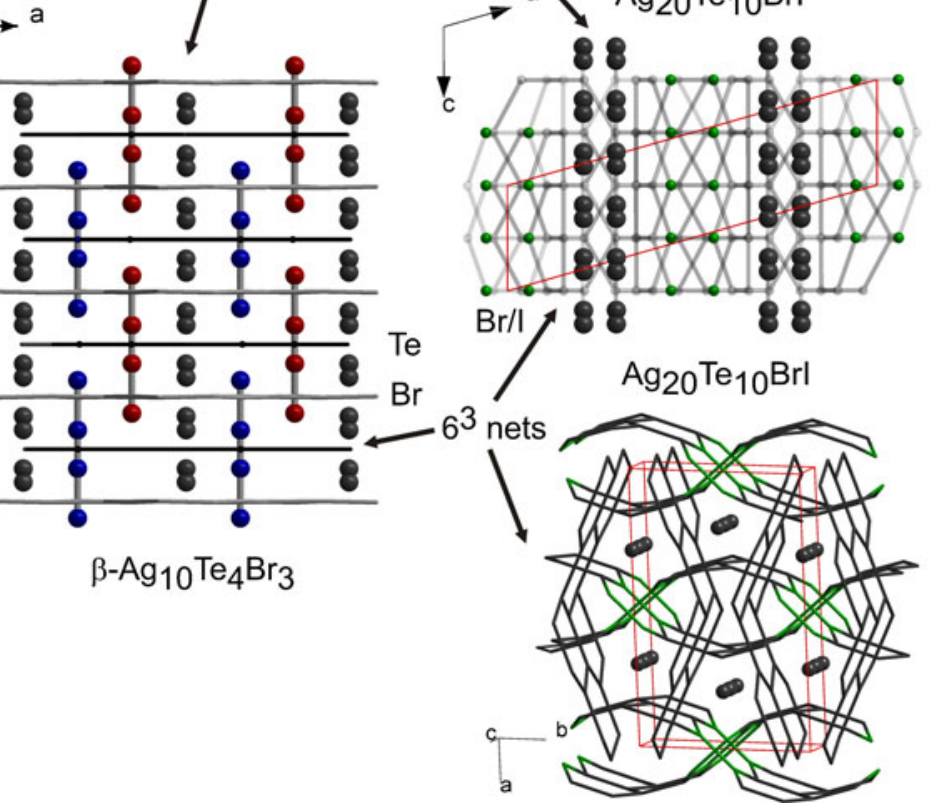

Fig. 3. Precession photographs, crystal structures (anion substructures only), and diffuse scattering phenomena of $\mathrm{Ag}_{10} \mathrm{Te}_{4} \mathrm{Br}_{3}{ }^{19}$ and $\mathrm{Ag}_{20} \mathrm{Te}_{10} \mathrm{Brl}$. Due to the frustration of the Peierls-distorted Te chains a diffuse scattering phenomenon results, which can be observed along the direction of the chains in the precession photographs (marked by red arrows). The formation of the Peierls-distorted chain is given as a scheme in the middle of the figure.

comparable Te substructure, have been observed in $\mathrm{Ag}_{20} \mathrm{Te}_{10} \mathrm{BrI}$ (for the crystal structure and the Peierls distortion, see Fig. 3). In contrast to the latter, $\mathrm{Ag}_{20} \mathrm{Te}_{10} \mathrm{BrI}$ shows no structural phase transition in the temperature range from $113 \mathrm{~K}$ to the peritectic decomposition temperature. This aspect has been verified by differential scanning calorimetry (DSC) measurements and temperaturedependent single-crystal structure determinations at $293 \mathrm{~K}$ and $150 \mathrm{~K}$. There was no evidence for an ordering of silver or of the Te chains detectable in either experiment.

Quantum-chemical calculations of the polyanionic Te chain and solid-state ${ }^{125} \mathrm{Te}$ nuclear magnetic resonance (NMR) spectroscopy of $\mathrm{Ag}_{10} \mathrm{Te}_{4} \mathrm{Br}_{3}$ substantiated the increasing mobility (forming and breaking of covalent Te-Te bonds along the chain) of the Te chain overtaking the NMR timescale at elevated temperatures. ${ }^{23}$ A development of a Peierls-distorted chain toward an equidistant one 


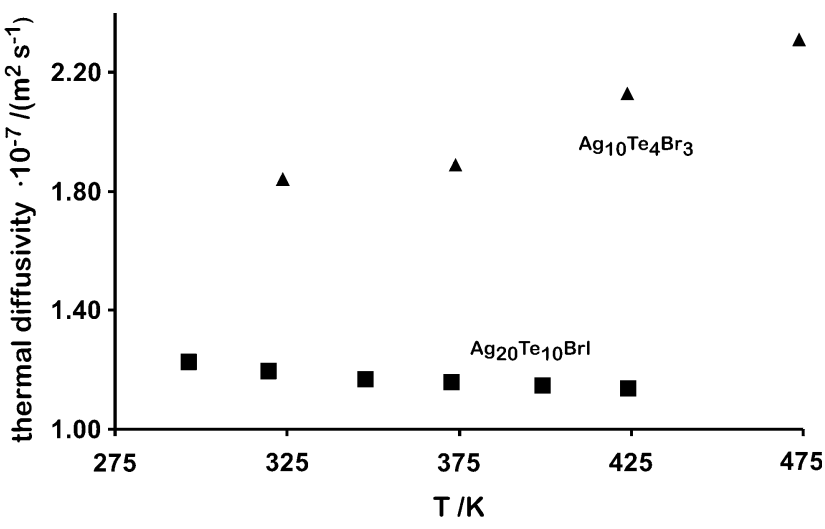

Fig. 4. Thermal diffusivity data of $\mathrm{Ag}_{10} \mathrm{Te}_{4} \mathrm{Br}_{3}$ and $\mathrm{Ag}_{20} \mathrm{Te}_{10} \mathrm{Brl}$.

results in a significant closing of the bandgap, which is a well-known fact in the case of $\mathrm{Sb}$ or $\mathrm{Te}$ chains. $^{23,42}$ Exactly when the Q-chain mobility becomes high and the bandgap gets closed from $1.1 \mathrm{eV}$ to approximately $0.7 \mathrm{eV}$, a huge and formerly unseen thermopower drop of about $1400 \mu \mathrm{V} \mathrm{K}^{-1}$ occurs. Bandgap tuning results in a change of the semiconduction mechanism from $p$ to $n$ and back to $p$ conduction at the same time within a temperature region of $375 \mathrm{~K}$ to $410 \mathrm{~K} .^{23}$ While $\delta$-, $\gamma$-, and $\beta$ - $\mathrm{Ag}_{10} \mathrm{Te}_{4} \mathrm{Br}_{3}$ are $p$-type semiconductors a switch to $n$-type conduction was observed during the broad $\beta-\alpha$ phase transition. $\alpha-\mathrm{Ag}_{10} \mathrm{Te}_{4} \mathrm{Br}_{3}$ again is a $p$-type conductor. This process was substantiated by temperature-dependent potentiometric measurements and Hebb-Wagner polarization experiments. Based on our electrochemical examinations none of the aforementioned (poly)chalcogenide halides show a huge variation in the coinage-metal content as in intermetallic compounds and the nonstoichiometry range seems to be very small in all cases.

As a result of two mobile substructures (cations and polyanionic chalcogen part) the coinage-metal (poly)chalcogenide halides are supposed to be effective phonon-scattering materials. For $\mathrm{Ag}_{10} \mathrm{Te}_{4} \mathrm{Br}_{3}$ a thermal conductivity of $0.27 \mathrm{~W} \mathrm{~m}^{-1} \mathrm{~K}^{-1}$ to $0.43 \mathrm{~W} \mathrm{~m}^{-1} \mathrm{~K}^{-1}$ was observed in the temperature range of $250 \mathrm{~K}$ to $350 \mathrm{~K} \cdot{ }^{23}$ Compared with the roomtemperature thermal conductivity of $\mathrm{Ag}_{2} \mathrm{Te}^{43}$ of $0.93 \mathrm{~W} \mathrm{~m}^{-1} \mathrm{~K}^{-1}$, the conductivity is reduced by a factor of $\sim 3$ at this temperature. Figure 4 shows the results of thermal diffusivity measurements for $\mathrm{Ag}_{10} \mathrm{Te}_{4} \mathrm{Br}_{3}$ and $\mathrm{Ag}_{20} \mathrm{Te}_{10} \mathrm{BrI}$. The low thermal diffusivity of $\mathrm{Ag}_{10} \mathrm{Te}_{4} \mathrm{Br}_{3}$ of about $1.9 \times 10^{-7} \mathrm{~m}^{2} \mathrm{~s}^{-1}$ is again lowered to $1.1 \times 10^{-7} \mathrm{~m}^{2} \mathrm{~s}^{-1}$ in the case of $\mathrm{Ag}_{20} \mathrm{Te}_{10} \mathrm{BrI}$ (Fig. 4). Both thermal diffusivities are comparable to the values of classical isolators such as polyethylene $\left(2.2 \times 10^{-7} \mathrm{~m}^{2} \mathrm{~s}^{-1}\right)^{44}$ and polyvinylchloride $\left(1 \times 10^{-7} \mathrm{~m}^{2} \mathrm{~s}^{-1}\right){ }^{45} \mathrm{~A}$ brief summary of the thermal diffusivity data is given in Table III.

All experiments performed in the present class of materials point toward the fact that the linear,
Table III. Thermal diffusivity data of $\mathrm{Ag}_{10} \mathrm{Te}_{4} \mathrm{Br}_{3}$ and $\mathrm{Ag}_{20} \mathrm{Te}_{10} \mathrm{BrI}$

\begin{tabular}{|c|c|c|c|}
\hline $\mathrm{Ag}_{10} \mathrm{Te}_{4} \mathrm{Br}_{3}$ & $\begin{array}{c}\text { Temperature } \\
T \text { (K) }\end{array}$ & $\begin{array}{c}\text { Thermal } \\
\text { Diffusivity } \\
a 1^{-7} \\
\left(\mathbf{m}^{2} \mathbf{s}^{-1}\right)\end{array}$ & References \\
\hline \multirow{13}{*}{$\mathrm{Ag}_{20} \mathrm{Te}_{10} \mathrm{BrI}$} & $324(1)$ & 1.84 & \multirow[t]{4}{*}{23} \\
\hline & $374(1)$ & 1.89 & \\
\hline & $424(1)$ & 2.13 & \\
\hline & $474(1)$ & 2.31 & \\
\hline & $223(1)$ & $1.44(7)$ & This work \\
\hline & $248(1)$ & $1.33(5)$ & \\
\hline & 273(1) & $1.28(7)$ & \\
\hline & 296(1) & $1.23(6)$ & \\
\hline & $319(1)$ & $1.20(6)$ & \\
\hline & $348(1)$ & $1.17(4)$ & \\
\hline & $372(1)$ & $1.16(3)$ & \\
\hline & $399(1)$ & $1.15(3)$ & \\
\hline & $424(1)$ & $1.144(8)$ & \\
\hline
\end{tabular}

partially covalent-bonded Q chain, in addition to the high and effective coordination behavior of the coinage-metal cations, is an effective way to generate favorable electronic properties. The redox reaction itself may have certain potential to be used as an electrochemical redox switch or as a currentdriven resistance switch after material optimization and successful thin-film preparation of the materials. ${ }^{46}$ At least the evolution of the thermopower in $\mathrm{Ag}_{10} \mathrm{Te}_{4} \mathrm{Br}_{3}$ as well as the thermal diffusivity of $\mathrm{Ag}_{20} \mathrm{Te}_{10} \mathrm{BrI}$ are promising features to check the opportunity of these materials as potential thermoelectrics or sensors. Even use of the drastic switching effect in data-storage applications may be possible if a properly ordered and oriented thin-film preparation of the crystalline material could be achieved. Each chain shows a distance of approximately $0.75 \mathrm{~nm}$ to the next neighbor chain, which reduces the density of switchable substructures to the subnanometer regime.

\section{CONCLUSIONS}

An easy and straightforward principle of structure topology is the basis for a deep understanding of the electronic structure of a new class of highly dynamic coinage-metal (poly)chalcogenide halides. A linear, partially covalent-bonded and mobile chain of chalcogen has been identified as the origin of a temperature-driven redox reaction in the solid state. In combination with the intrinsically mobile cation substructure of these mixed ion/electronconducting semiconductors, this class of materials is a rare example of a system combining two independent mobile substructures in the solid state. As a result, the thermal conductivity and diffusivity of such systems is drastically reduced to values comparable and even slightly lower than today's 
state-of-the-art nanostructured thermoelectrics (such as superlattices and quantum dots). This extremely low thermal conductivity is reached by bulk phase material without nanostructuring or material optimization. Such a redox reaction causes bandgap tuning due to modification of the units ( $Q$ chains) making a major contribution to electronic states around the bandgap.

Recently, during the refereeing process of this article, the general principle of a Peierls-distortion of a distinct building unit, has been identified as a powerful tool for high thermoelectric performance in $\mathrm{In}_{4} \mathrm{Se}_{3-\delta}$, also substantiating the potential of the general method described here. ${ }^{47}$

As stated by Prof. Jansen itself in a recent article, ${ }^{48}$ the frustration of building blocks (like the present distortion phenomena here) is again a key ingredient for unconventional phenomena in solid materials.

\section{ACKNOWLEDGEMENTS}

This project is financed by the DFG within the Collaborative Research Center SFB 458 Ionic motion in materials with disordered structures. We thank Netzsch, Germany for the measurement of the thermal diffusivity of $\mathrm{Ag}_{20} \mathrm{Te}_{10} \mathrm{BrI}$.

\section{REFERENCES}

1. B.C. Sales, Int. J. Ceram. Technol. 4, 291 (2007). doi: 10.1111/j.1744-7402.2007.02143.x.

2. C.B. Vining, Nat. Mater. 8, 83 (2009). doi:10.1038/nmat2361.

3. K.F. Hsu, S. Loo, F. Guo, W. Chen, J.S. Dyck, C. Uher, T. Hogan, E.K. Polychroniadis, and M.G. Kanatzidis, Science 303,818 (2004). doi:10.1126/science.1092963.

4. T.C. Harman, P.J. Taylor, D.L. Spears, and M.P. Walsh, J. Electron. Mater. 29, L1 (2000). doi:10.1007/s11664-0000117-1.

5. T.C. Harman, M.P. Walsh, B.E. Laforge, and G.W. Turner, J. Electron. Mater. 34, L19 (2005). doi:10.1007/s11664-0050083-8.

6. R. Venkatasubramanian, E. Siivola, T. Colpitts, and B. O'Quinn, Nature 413, 597 (2001). doi:10.1038/35098012.

7. X-RED 32, version 1.10; Stoe \& Cie GmbH: Darmstadt, Germany (2004) and X-SHAPE, version 2.05; Stoe \& Cie GmbH: Darmstadt, Germany (2004).

8. V. Petříček, M. Dušek, and L. Palatinus, The Crystallographic Computing System JANA2006 (Praha, Czech Republic: Institute of Physics, 2006).

9. W.F. Kuhs, Acta Crystallogr. Sect. A 48, 80 (1992). doi: 10.1107/S0108767391009510.

10. R. Blachnik and G. Kudermann, Z. Naturforsch. 28b, 1 (1973).

11. R. Blachnik and H.A. Dreisbach, J. Solid State Chem. 60, 115 (1985). doi:10.1016/0022-4596(85)90171-9.

12. T. Doert, E. Rönsch, F. Schnieders, P. Böttcher, and J. Sieler, Z. Anorg. Allg. Chem. 626, 89 (2000).

13. T. Nilges, S. Nilges, A. Pfitzner, T. Doert, and P. Böttcher, Chem. Mater. 16, 806 (2004). doi:10.1021/cm031131c.

14. M. Bawohl and T. Nilges, Z. Naturforsch. 63b, 1083 (2008).

15. J. Messel and T. Nilges, Z. Naturforsch. 63b, 1077 (2008).

16. T. Nilges, J. Messel, M. Bawohl, and S. Lange, Chem. Mater. 20, 4080 (2008). doi:10.1021/cm800425u.
17. T. Nilges and J. Messel, Z. Anorg. Allg. Chem. 634, 2185 (2008). doi:10.1002/zaac.200800128.

18. S. Lange and T. Nilges, Chem. Mater. 18, 2538 (2006). doi: $10.1021 / \mathrm{cm} 060226 \mathrm{~m}$.

19. S. Lange, M. Bawohl, D. Wilmer, H.-W. Meyer, H.-D. Wiemhöfer, and T. Nilges, Chem. Mater. 19, 1401 (2007). doi:10.1021/cm062731p.

20. T. Nilges, M. Bawohl, and S. Lange, Z. Naturforsch. 62b, 955 (2007)

21. T. Nilges and M. Bawohl, Z. Naturforsch. 63b, 629 (2008).

22. S. Lange, M. Bawohl, and T. Nilges, Inorg. Chem. 47, 2625 (2008). doi:10.1021/ic701988u.

23. T. Nilges, S. Lange, M. Bawohl, J.-M. Deckwart, H.-D. Wiemhöfer, R. Decourt, B. Chevalier, J. Vannahme, H. Eckert, and R. Weihrich, Nat. Mater. 8, 101 (2009). doi: 10.1038/NMAT2358.

24. J. Peters, O. Conrad, B. Bremer, and B. Krebs, Z. Anorg. Allg. Chem. 622, 1823 (1996). doi:10.1002/zaac.19966221105.

25. H.-J. Deiseroth and H. Mikus, Z. Anorg. Allg. Chem. 631, 1233 (2005). doi:10.1002/zaac.200500018.

26. J.S. Wu, K. Leinenweber, J.C.H. Spence, and M. O'Keeffe, Nat. Mater. 5, 647 (2006). doi:10.1038/nmat1687.

27. L. Palatinus, Acta Crystallogr. Sect. A 60, 604 (2004). doi: 10.1107/S0108767304022433.

28. G. Oszlányi and A. Sütő, Acta Crystallogr. Sect. A 60, 134 (2004). doi:10.1107/S0108767303027569.

29. G. Oszlányi and A. Sütő, Acta Crystallogr. Sect. A 61, 147 (2005). doi:10.1107/S0108767304027746.

30. T. Nilges, C. Dreher, and A. Hezinger, Solid State Sci. 7, 79 (2005). doi:10.1016/j.solidstatesciences.2004.10.012.

31. T. Nilges and S. Lange, Z. Anorg. Allg. Chem. 631, 3002 (2005). doi:10.1002/zaac.200500261.

32. R. Ollitrault-Fichet, J. Rivet, J. Flahaut, and C.E. Kfouri, J. Solid State Chem. 110, 80 (1994). doi:10.1006/jssc.1994. 1139.

33. M. Gobec and W. Sitte, J. Alloys Compd. 220, 152 (1995). doi:10.1016/0925-8388(94)06000-2.

34. I. Schewe and P. Böttcher, Z. Naturforsch. 45b, 417 (1990).

35. I. Schewe-Miller and P. Böttcher, Z. Kristallorgr. 196, 137 (1991).

36. K. Seifert-Lorenz and J. Haffner, Phys. Rev. B. Condens. Matter 66, 094105 (2002). doi:10.1103/PhysRevB.66.094105.

37. P. Böttcher, G. Getzschmann, and R. Keller, Z. Anorg. Allg. Chem. 619, 476 (1993). doi:10.1002/zaac.19936190309.

38. B. Eisenmann and H. Schäfer, Angew. Chem. 90, 731 (1978); Angew. Chem. Int. Ed. 17, 684 (1978). doi:10.1002/anie.1978 06841.

39. T. Ono, I. Yoshida, and M. Sakurai, Proceedings of the 19th International Conference on Thermoelectrics (2000), p. 370.

40. O. Osters and T. Nilges, unpublished results.

41. E. Ising, Z. Phys. 31, 253 (1925).

42. G.A. Papoian and R. Hoffmann, Angew. Chem. Int. Ed. 39, 2408 (2000). doi:10.1002/1521-3757(20000717)112:14<2500: AID-ANGE2500 $>3.0 . C O ; 2-T$.

43. M. Fujikane, K. Kurosaki, H. Muta, and S. Yamanaka J. Alloys Compd. 393, 299 (2005). doi:10.1016/j.jallcom.2004. 10.002 .

44. G. Kalaprasad, P. Pradeep, G. Mathew, C. Pavithran, and S. Thomas, Compos. Sci. Technol. 60, 2967 (2000). doi: 10.1016/S0266-3538(00)00162-7.

45. M. Hattori, Kolloidzeitschrift und Zeitschrift für Polymere (Colloid Polym. Sci.) 1, 11 (1964).

46. J. Janek, Nat. Mater. 8, 88 (2009). doi:10.1038/nmat2364.

47. J.-S. Rhyee, K.H. Lee, S.M. Lee, E. Cho, S.I. Kim, E. Lee, Y.S. Kwon, J.H. Shim, and G. Kotliar, Nature 459, 965 (2009). doi:10.1038/nature08088.

48. H. Yoshida, S. Ahlert, M. Jansen, Y. Okamoto, J.-I. Yamaura, and Z. Hiroi, J. Phys. Soc. Jpn. 77, 074719/1 (2008). 